\title{
Dense bottlebrushes enable supersoft solvent-free networks
}

\author{
Florian J Stadler and Bing Du
}

NPG Asia Materials (2016) 8, e276; doi:10.1038/am.2016.69; published online 3 June 2016

Daniel et al. ${ }^{1}$ demonstrated the effectiveness of dense bottlebrush polymers in lowering the entanglement density, that is, reducing the physical interaction level, by stiffening the main chains through the growth of numerous side chains-the bottlebrush structure. This breakthrough work is based on earlier works of the late Pakula. ${ }^{2}$ Sheiko's group has been working on this topic for several years (as summarized in Lee et al. ${ }^{3}$ and Sheiko et $a .^{4}$ ), but they have reported only results on minute amounts of materials. Hence, the physical behavior of bottlebrushes has not been tested on a macroscopic level. To do so effectively means diluting polymer chains by themselves instead of adding a solvent, as it has classically been done with gels and solutions.

In addition, these bottlebrushes were crosslinked with each other, leading to a rubber-like system, albeit with a significantly lower cross-link density than that of conventional rubbers. The clear consequence is that the properties of cross-linked bottlebrushes fall between those of very soft rubbers, which typically lack entanglements and have very few cross-links, and gels, which typically contain 75-99\% solvent (Scheme 1). Another decisive difference is that polymers and solvents always possess complicated interaction patterns; for example, hydrogels can eject water upon compression. Furthermore, because the chains in gels 'swim' in water, they can be moved individually, which leads to easy crack propagation and thus to poor mechanical properties. Daniel et al. ${ }^{1}$ demonstrated that the mechanical properties in the compression of cross-linked bottlebrush gels were superior to those of a hydrogel with comparable polymer content (assuming that the hairs of the bottlebrushes are 'solvent').

The rheological properties of uncross-linked bottlebrushes resemble those of a Rouse chain - a behavior that is also observed in unentangled ring polymers. ${ }^{5}$ This behavior, which is rarely observed in the pure state, is the fingerprint of the absence of entanglement dynamics; that is, it proves that the hairs of the bottlebrush screen the main chain from entangling with other chains. Upon cross-linking, the bottlebrush shows a rubbery plateau, depending on the cross-linking density.

In this paper, a new class of materials for polymer physics is introduced that will certainly become important for the basic understanding of connections between polymer architecture and mechanical properties. In addition, the property of very low stiffness without the addition of solvents could find application in, for example, the biomedical area. In the future, it would be desirable to study the differences between dendrimers and bottlebrushes, that is, between round and stretched soft particles, and their interactions with conventional polymers. Moreover, the paper presents molecular theories and scaling laws that could be significantly expanded on by applying advanced molecular models. It remains an open question as to how large amounts of side chains behave in comparison with solvent, which could be studied by making a clearer comparison based on rheological mesoscale theories.

1 Daniel, W. F., Burdynska, J., VatankhahVarnoosfaderani, M., Matyjaszewski, K., Paturej, J., Rubinstein, M., Dobrynin, A. V. \& Sheiko, S. S. Solvent-free, supersoft and superelastic bottlebrush melts and networks. Nat. Mater. 15, 183-189 (2016).

2 Pakula, T., Zhang, Y., Matyjaszewski, K., Lee, H. I., Boerner, H., Qin, S. H. \& Berry, G. C. Molecular brushes as super-soft elastomers. Polymer 47, 7198-7206 (2006)

3 Lee, H. I., Pietrasik, J., Sheiko, S. S. \& Matyjaszewski, K. Stimuli-responsive molecular brushes. Prog. Polym. Sci. 35, 24-44 (2010).

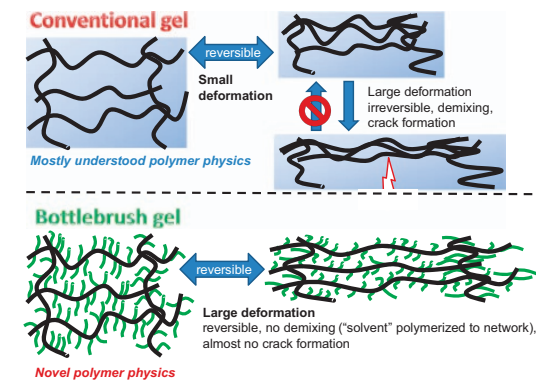

Scheme 1 Representation of the main differences between conventional gels and solvent-free bottlebrush gels.

4 Sheiko, S. S., Sumerlin, B. S. \& Matyjaszewski, K. Cylindrical molecular brushes: synthesis, characterization, and properties. Prog. Polym. Sci. 33, 759-785 (2008).

5 Kapnistos, M., Lang, M., Vlassopoulos, D., Pyckhout-Hintzen, W., Richter, D., Cho, D., Chang, T. \& Rubinstein, M. Unexpected power-law stress relaxation of entangled ring polymers. Nat. Mater. 7, 997-1002 (2008).

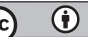

This work is licensed under a Creative Commons Attribution 4.0 International License. The images or other third party material in this article are included in the article's Creative Commons license, unless indicated otherwise in the credit line; if the material is not included under the Creative Commons license, users will need to obtain permission from the license holder to reproduce the material. To view a copy of this license, visit http:// creativecommons.org/licenses/by/4.0/

\footnotetext{
College of Materials Science and Engineering, Shenzhen Key Laboratory of Polymer Science and Technology, Guangdong Research Center for Interfacial Engineering of Functional Materials, Nanshan District Key Lab for Biopolymers and Safety Evaluation, Shenzhen University, Shenzhen, China

E-mail: fjstadler@szu.edu.cn
} 